\title{
Antitumor Effects of Lidocaine on Human Breast Cancer Cells: An In Vitro and In Vivo Experimental Trial
}

\author{
THIÊN-NGA CHAMARAUX-TRAN ${ }^{1,2,3,4,5}$, CAROLE MATHELIN ${ }^{2,3,4,5,6}$, MARC APRAHAMIAN ${ }^{7}$, \\ GIRISH P. JOSHI ${ }^{8}$, CATHERINE TOMASETTO ${ }^{2,3,4,5}$, PIERRE DIEMUNSCH ${ }^{1,5,7}$ and CHERIF AKLADIOS ${ }^{5,6,7}$ \\ Departments of ${ }^{1}$ Anesthesiology and Surgical Intensive Care, and ${ }^{6}$ Gynecology and Obstetrics, \\ Hautepierre Hospital, CHRU, University Hospital of Strasbourg, Strasbourg, France; \\ ${ }^{2}$ Functional Genomics and Cancer Department, \\ Institute of Genetics and Molecular and Cellular Biology (IGBMC), Illkirch, France; \\ ${ }^{3}$ French National Center for Scientific Research (CNRS) UMR7104, Illkirch, France; \\ ${ }^{4}$ French National Institute of Health and Medical Research (INSERM) U964, Illkirch, France; \\ ${ }^{5}$ Faculty of Medicine, University of Strasbourg, Strasbourg, France; \\ ${ }^{7}$ Research Institute against Digestive Cancer - European Institute of TeleSurgery (IRCAD), Strasbourg, France; \\ ${ }^{8}$ Department of Anesthesiology and Pain Management, \\ University of Texas Southwestern Medical Center, Dallas, TX, U.S.A.
}

\begin{abstract}
Aim: Retrospective studies have suggested a protective effect of regional anesthesia against recurrence after cancer surgery. But confirmation of the in vivo antitumor effects is lacking. We examined the in vitro antitumor effects of lidocaine on various breast cancer cell lines and then assessed these properties in vivo at clinically relevant concentrations. Materials and Methods: In vitro experiments: normal breast epithelial cells (NBEC) MCF$10 A$ and three tumor breast epithelial cells (TBEC) lines (MCF-7 luminal A, MDA-MB-231 triple-negative and SKBr3 $H E R 2$ positive) were exposed to increasing concentrations of lidocaine. Cell viability, migration and anchorageindependent growth were assessed by MTT, wound healing, and soft-agar growth assays. In vivo experiments: 6-weekold severe combined immunodeficient mice were injected intraperitoneally with MDA-MB-231 cells and were treated with intraperitoneal lidocaine or phosphate-buffered saline. The mice were euthanized when they reached experimental endpoints or sacrificed to determine peritoneal carcinomatosis index and global tumor volumes. Results: Lidocaine reduced the viability of all the cell lines, inhibited
\end{abstract}

Correspondence to: Thiên-Nga Chamaraux-Tran, MD, IGBMC CNRS UMR 7104 - Inserm U 964, Team Tomasetto, 1, rue Laurent Fries, BP 10142, 67404 Illkirch Cedex, France. Tel: +33 0388653423, e-mail: chamarau@igbmc.fr

Key Words: Local anesthetics, lidocaine, breast cancer, xenograft model antitumor assays, MDA-MB-231 cell line. migration of TBEC compared to the NBEC, and compromised the anchorage-independent growth of the triple-negative cells. Intraperitoneal lidocaine improved survival of mice with MDA-MB-231 peritoneal carcinomatosis using doses that are consistent with the current clinical settings for analgesia. Conclusion: In agreement with the notion that local anesthesia may be beneficial for cancer therapy, lidocaine has a protective effect against breast cancer cells in experimental studies. However, the beneficial impact of local anesthetics on breast cancer needs to be strengthened by additional preclinical and clinical trials.

Breast cancer is the most commonly diagnosed cancer and the second cause of cancer-related death after lung cancer in women (1). Patients are increasingly opting for mastectomy; therefore, the number of breast surgery procedures has increased in recent years (2). The perioperative period is considered as a period of risk, since in some cases, surgery may be associated with cancer cell shedding and may have a metastasis-promoting effect (3-6).

Several retrospective studies have suggested an impact of anesthesia on survival of patients with cancer (7); notably, regional anesthesia is associated with a reduced risk of cancer relapse or recurrence $(8,9)$. One of the proposed hypotheses to explain these observations includes the opioidsparing effects of regional anesthesia. Opioids have been implicated in promoting cancer progression $(10,11)$. Another possible reason for the improved cancer outcomes with regional anesthesia may be related to the antitumor effects 
of local anesthetics, including prevention of proliferation, migration or invasion of cancer cells $(12,13)$. Perioperative intravenous lidocaine infusion has been shown to reduce postoperative pain and opioid requirements $(14,15)$. Lidocaine has also been shown to induce apoptosis and suppress tumor growth in human breast tumor cells (16) as well as other in vitro tumor cells $(12,17-21)$. Additionally, it has been reported to enhance sensitization of breast cancer cells to chemotherapeutic drugs (22).

Although there are several in vitro studies assessing the antitumor effects of lidocaine, there is limited evidence of its effects in vivo (21). Moreover, the lidocaine concentrations used in these in vitro experiments may fit with infiltration use but were higher than those observed after systemic administration (23). Thus, there is a need to test the antitumor properties of lidocaine at doses relevant to systemic administration, notably, using doses which have been shown to improve recovery and prevent chronic pain in patients undergoing breast cancer surgery (24). In addition, it is postulated that lidocaine may exert antitumor properties through different mechanisms: directly on cell growth, inducing apoptosis or inhibiting proliferation, and indirectly by preserving natural killer cell activity (23), modulating pro-inflammatory macrophages, modifying mesenchymal stromal cells and then the local microenvironment (25-27). All these possible actions of lidocaine remain to be tested in a relevant preclinical model. The aim of this study was to evaluate the in vitro antitumor effects of lidocaine on several human breast cancer cell lines completed by in vivo assessment of the effects of lidocaine in a preclinical model of cancer.

\section{Materials and Methods}

\section{In vitro Experiments}

Cells and cell culture. Three human breast cancer cell lines representatives of the three main molecular subtypes used throughout this study were obtained from the American Type Culture Collection (Manassas, VA, USA): MCF-7 [estrogen (ER) and progesterone receptor (PgR)-positive], SKBR3 (ER- and PgR-negative) which has a high level of erb-b2 receptor tyrosine kinase 2 (ERBB2) oncogene amplification, and MDA-MB-231 (ER- and PgR-negative, no amplification of ERBB2 oncogene). When appropriate, they were compared to a non-tumorigenic mammary epithelial cell line: MCF10A. The detailed characteristics of the tumor cell lines are described elsewhere (28). MCF-7 and SKBR3 cells were grown in Dulbecco's modified Eagle's medium (DMEM) enriched with $10 \%$ fetal calf serum (FCS), $2 \mathrm{mM}$ glutamine, $50 \mu \mathrm{g} / \mathrm{ml}$ gentamycin in an atmosphere of $5 \%$ carbon dioxide $\left(\mathrm{CO}_{2}\right)$ and $95 \%$ air at $37^{\circ} \mathrm{C}$. Cell culture medium for MCF-7 was supplemented with bovine insulin (0.6 $\mu \mathrm{g} / \mathrm{ml})$. MDA-MB-231 cells were grown in RPMI-1640 without HEPES and enriched with $10 \%$ FCS and gentamycin $(40 \mu \mathrm{g} / \mathrm{ml})$. MCF-10A were grown in DMEM (1g/l glucose)/HAM F12 (3:1) enriched with $20 \mu \mathrm{g} / \mathrm{ml}$ adenine, $5 \mu \mathrm{g} / \mathrm{ml}$ insulin, $5 \mu \mathrm{g} / \mathrm{ml}$ human apo-transferrin, $1.5 \mathrm{ng} / \mathrm{ml}$ triiodothyronine, $2 \mathrm{ng} / \mathrm{ml}$ human epidermal growth factor (hEGF), $0.5 \mu \mathrm{g} / \mathrm{ml}$ hydrocortisone, $10 \%$ FCS and 40 $\mu \mathrm{g} / \mathrm{ml}$ gentamicin. Subculturing was routinely carried out every week using diluted trypsin solution $(0.25 \%)$ in Dulbecco's phosphate buffered saline (DPBS) without calcium and magnesium ( $\mathrm{pH}$ 7.2).

Drug treatment. To perform in vitro experiments, lidocaine and lidocaine hydrochloride monohydrate were obtained in a pure powder form (MW 234.34 and MW 288.81 respectively; SigmaAldrich, St. Louis, MO, USA). A stock solution $(50 \mathrm{mg} / \mathrm{ml}$ in absolute ethanol, and water, respectively) was freshly prepared and increasing drug concentrations $(0.1,0.5,1,5$ and $10 \mathrm{mM})$ were obtained by diluting the stock solution in cell culture medium. We controlled for the $\mathrm{pH}$ of final media containing lidocaine or vehicle ensuring they were in the same normal range.

3-(4,5 Dimethylthiazol-2-yl) 2,5 diphenyl-tetrazolium bromide (MTT) assay. This rapid colorimetric assay was elaborated by Mosmann for cellular growth and survival (29). For each cell line, exponentially growing cells were enzymatically detached and a single tumor cell suspension in culture medium at a density of $30 \times 10^{3}$ cells $/ \mathrm{ml}$ was prepared. Cells were seeded in 24-well microtiter plates $(1 \mathrm{ml} /$ well) and allowed to attach for $24 \mathrm{~h}$ under the previous specified conditions. Culture medium in each well was aspirated and replaced with fresh culture medium containing different lidocaine concentrations and cells were allowed to grow for a further $4 \mathrm{~h}$. Triplicate wells were used for controls (absolute ethanol as vehicle alone) and each concentration. The cell viability was then determined by the MTT assay (30) with minor modifications. In brief, $100 \mu \mathrm{l}$ of MTT $(2 \mathrm{mg} / \mathrm{ml}$ in DPBS $)$ were added and the plates were incubated at $37^{\circ} \mathrm{C}$ for $1 \mathrm{~h}$ in the dark. This assay is based on the cleavage of the tetrazolium salt by viable cells and the accumulation of a water insoluble formazan salt proportional to the number of living cells in the well. After careful aspiration of the culture medium, $150 \mu \mathrm{l}$ of dimethylsulfoxide were added to each well and the plates were incubated for a further $1 \mathrm{~h}$. The plates were read at wavelength $595 \mathrm{~nm}$ with reference to the appropriate blank (dimethylsulfoxide only) in a 96-wells microplate spectrophotometer (Biorad Laboratories, Hercules, CA, USA).

Cell migration was assessed by gap closure in wound-healing assay. A cell monolayer was made by seeding $4 \times 10^{5}$ cells in 6 -well plates ( $2 \mathrm{ml} / \mathrm{well}$ ) for $24 \mathrm{~h}$. A scratch was then made using a $500 \mu \mathrm{l}$ tip to mimic an injury. The wells were then washed with PBS and medium without FCS containing $0.1 \mathrm{mM}$ of lidocaine or absolute ethanol as control and incubated for $24 \mathrm{~h}$ (and $48 \mathrm{~h}$ for MDA-MB-231 cells). Images were acquired at 0 and $24 \mathrm{~h}$ to measure the wound closure using ImageJ software (U.S. National Institutes of Health, Bethesda, MD, USA).

Soft-agar growth. Onto a culture plate was poured 0.6\% UltraPure Low Melting Point Agarose (Invitrogen, Carlsbad, CA, USA) in the appropriate medium with lidocaine hydrochloride monohydrate, or water as control. On the top of this layer, a gel containing $5 \times 10^{3}$ MDA-MB-231 cells in 0.3\% UltraPure Low Melting Point Agarose in appropriate cell medium and lidocaine hydrochloride monohydrate concentration, or water as control, was added. After 19 days of culture, stained colonies $(1 \mathrm{mg} / \mathrm{ml}$ MTT) were visualized and counted using ImageJ software.

\section{In Vivo Animal Experiments}

Given that lidocaine affects cancer cell viability and migration in vitro, we extended this study to an in vivo preclinical model of 
cancer. In order to study the antitumor effects of lidocaine on MDAMB-231 tumor cell line in vivo, a tumor model of peritoneal carcinomatosis in the Mouse was used.

Tumor model of peritoneal carcinomatosis. To generate intraperitoneal xenograft tumors, 5- to 6-week-old severe combined immunodeficiency (SCID) female mice (20 g in weight; Envigo, Gannat, France) were injected intraperitoneally with a suspension of $5 \times 10^{6}$ MDA-MB 231 tumor cells in $200 \mu$ l of Hanks' Balanced Salt Solution. Mice were clinically checked three times a week and were sacrificed when mice developed tumor side-effects such as ascites or reduced general condition with weight loss or bad grooming which constituted our experimental endpoints. All animal experiments were carried out according to the revised European Community directive $(2010 / 63 / \mathrm{EU}$, September 24,2010$)$ on the protection of animals used for scientific purposes and with an ethical agreement (no. 38.2012.01.046) according to the French transposition of the European Community directive.

Lidocaine dosage. Protocol of administration of lidocaine was designed to be relevant to general clinical practice: doses were chosen according to the current intraperitoneal lidocaine prescription used to reduce postoperative shoulder pain after laparoscopy ( $8 \mathrm{mg} / \mathrm{kg})(31)$; dose adjustment for mice was made using the body surface area normalization method (32) resulting in a dose of $100 \mu \mathrm{l} / 10 \mathrm{~g}$ body weight of lidocaine solution (Aguettant, Lyon, France) at a concentration of $10 \mathrm{mg} / \mathrm{ml}$. The repeated injection pattern was based on serial intravenous lidocaine infusions for the chronic management of patients with fibromyalgia (33) who received three injections of lidocaine at one-week intervals.

Experimental protocols. In a first group, used to determine the median survival of this peritoneal carcinomatosis model, 10 mice were inoculated with tumor cells as described above and were clinically examined three times a week until they were sacrificed when they reached the experimental endpoints. The obtained median survival day was used as the day of animal sacrifice in the determination of Sugarbaker index in the subsequent experiments.

In a second experiment, the first tumor reduction study with lidocaine treatment included two randomized groups of 10 mice each. The lidocaine group was injected intraperitoneally with $100 \mu \mathrm{l} / 10 \mathrm{~g}$ body weight of lidocaine solution (Aguettant) at a concentration of $10 \mathrm{mg} / \mathrm{ml}$ (or $100 \mathrm{mg} / \mathrm{kg}$ ) weekly from day 14 to day 28 after inoculation of the cancer cells. The control group was injected intraperitoneally with $100 \mu \mathrm{l}$ of PBS/10 g body weight using the same sequence protocol of injection. The animals were clinically examined three times a week until they were sacrificed when they reached the experimental endpoints and the corresponding median survival and log-rank tests were calculated. Mice were examined in a random order by an investigator who was blinded to drug-treatment group.

In order reduce the number of animals needed to be tested, a pilot study was designed with six mice in each group to determine survival rate and to perform a sample size calculation. According to a survival rate of 0.33 in the lidocaine-treated group and 0 in the control group at day 49 , we calculated that 10 mice in each group (10\% attrition included) would be required for the study to have $90 \%$ power with a two-sided alpha level of $5 \%$ for survival analysis (34). Because the materials and procedures used in the pilot study were similar to that in the main study, the data from the pilot study were incorporated into the main study.
In a second tumor reduction study, we used groups of five mice each devoted to the determination of peritoneal carcinomatosis index (PCI) according to Sugarbaker scaling adapted to small animals (35). Mice were randomly injected intraperitoneally with $100 \mu \mathrm{l} / 10 \mathrm{~g}$ body weight of lidocaine solution at a concentration of $10 \mathrm{mg} / \mathrm{ml}$ or with $100 \mu \mathrm{l} / 10 \mathrm{~g}$ body weight of PBS weekly from day 16 to day 28 after inoculation of the tumor cells. Animals were sacrificed at the day determined by the first in vivo experiment for PCI and tumor volume determined.

Determination of the Sugarbaker index and volume of the peritoneal carcinomatosis. Mice were euthanized via neck dislocation performed under inhalation anesthesia with $3 \%$ isoflurane (Forène, Abott, France) in $100 \%$ oxygen. The abdomen was opened by bilateral paramedian incision completed by a horizontal pubic incision generating a skin flap, which was folded upwards. The extent of peritoneal carcinomatosis was given by a modified peritoneal index (Sugarbaker index) adapted for tumor size and areas in rats as previously described (35). The resulting lesion size score was: 0 for no tumor seen, 1 for tumor up to $2 \mathrm{~mm}$ of diameter, 2 for tumor between 2 and $5 \mathrm{~mm}$, and 3 for tumor more than $5 \mathrm{~mm}$ or confluent. Thirteen areas were recorded and the maximum score was 39 .

After careful collection of all the tumors found in the different areas, the whole tumor volume was measured by water displacement (expressed in $\mathrm{cm}^{3}$ as $\mathrm{ml}$ equivalent). PCI and whole tumor volumes were assessed by an investigator who was blinded to drug-treatment group in random order for all animals.

Statistical analysis. Data are expressed as the mean \pm standard deviation. Each in vitro assay was performed in triplicate and at least three times. Results were compared with one-way repeatedmeasures ANOVA followed by a Dunnett test or Student's unpaired test where appropriate. Concerning in vivo data, tumor volumes, determined by water displacement, were tested for statistical differences between animal groups using one-way ANOVA followed by a parametric Student's unpaired $t$-test. Rodent survival curves were generated according to the Kaplan-Meier method (36) and differences between animal groups were put to the log-rank test. GraphPad InStat statistics software (GraphPad Software, Inc., La Jolla, CA, USA) was used for these analyses. $p$-Values of less than 0.05 were considered statistically significant.

\section{Results}

Lidocaine reduces cell viability of different human breast cancer cell lines. In order to test the effect of lidocaine on breast cancer cell viability, different cell lines were treated once with increasing dose of lidocaine for $4 \mathrm{~h}$. Viability was assayed using the MTT colorimetric test. In all cell lines, high doses of lidocaine impaired viability (Figure 1). Of interest, the tumor-derived breast cancer cell lines MCF-7 and Sk-Br-3 were similarly affected by lidocaine at concentrations of $1 \mathrm{mM}$ and more (Figure $1 \mathrm{~B}$ and $\mathrm{C}$ ). The triple-negative cell line MDA-MB-231 and normal cells MCF10A were more sensitive to lidocaine treatment, with a significant loss of viability at $0.5 \mathrm{mM}$ (Figure $1 \mathrm{~A}$ and D). Altogether these results indicate that lidocaine had a direct inhibitory effect on breast cell viability. 
A

MCF-10A

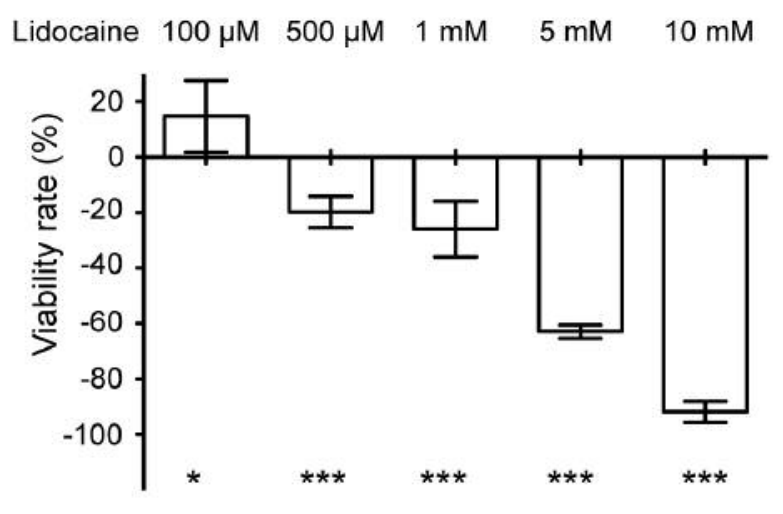

MDA-MB-231

Lidocaine $100 \mu \mathrm{M} \quad 500 \mu \mathrm{M} \quad 1 \mathrm{mM} \quad 5 \mathrm{mM} \quad 10 \mathrm{mM}$

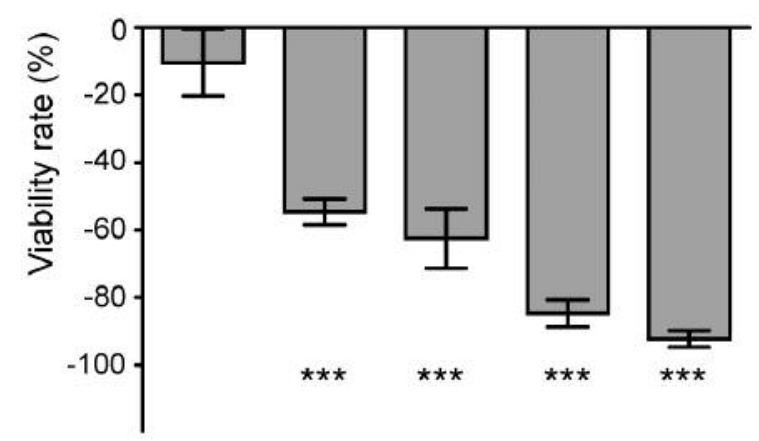

E

MCF-10A MCF-7 MDA-MB-231 SKBr3

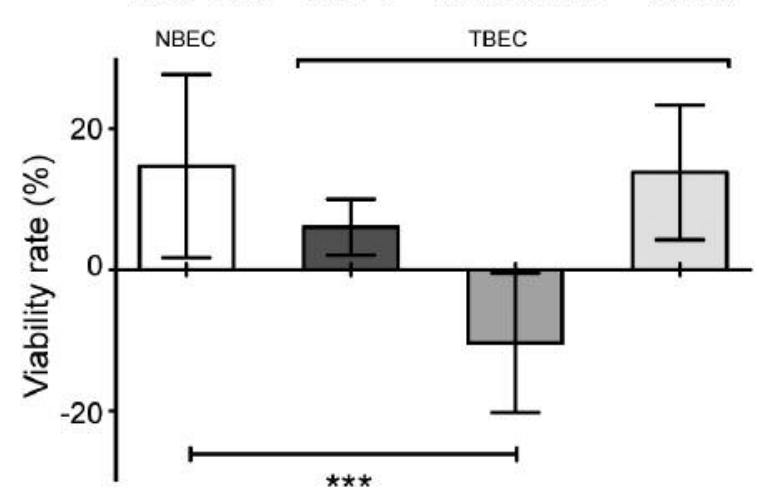

MCF-7

Lidocaine $100 \mu \mathrm{M} \quad 500 \mu \mathrm{M} \quad 1 \mathrm{mM} \quad 5 \mathrm{mM} \quad 10 \mathrm{mM}$

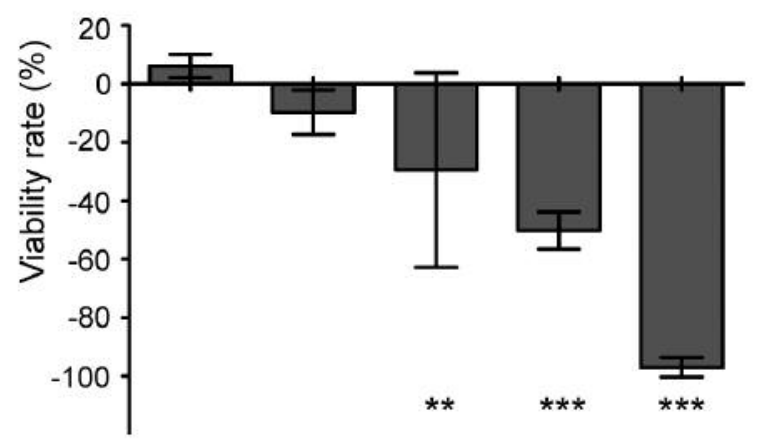

D

$\mathrm{SKBr} 3$

Lidocaine $100 \mu \mathrm{M} \quad 500 \mu \mathrm{M} \quad 1 \mathrm{mM} \quad 5 \mathrm{mM} \quad 10 \mathrm{mM}$

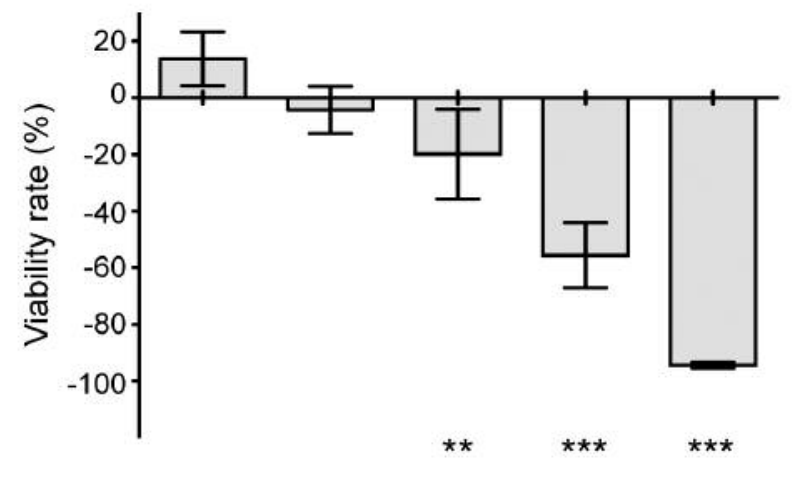

Figure 1. Effects of lidocaine on the viability of a panel of a breast epithelial cell lines: MCF10A normal cells (NBEC) and three tumorderived cell lines MDA-MB-231, MCF-7 and SkBr3 (TBEC). Cells were exposed to vehicle alone (control) or increasing concentrations of lidocaine (from 100 to $10 \mathrm{mM}$ ) for $4 \mathrm{~h}$ then an in vitro MTT colorimetric assay was performed for quantitative analysis (relative to the control) of the inhibitory effects on viability on MCF10A (A), MCF-7 (B), MDA$M B-231(C)$ and $S K B r 3(D)$ cell lines. Effect on viability was also compared amongst all cell lines under the lowest concentration of 100 $\mu M$ lidocaine (E). Data were analyzed by one-way repeated measures ANOVA: $p<0.0001$ for all the cell lines, and when comparing all the cell lines at $100 \mu \mathrm{M}$, followed by Dunnett's multiple comparison test (versus control): Significantly different at $* * p<0.01$ and $* * * p<0.001$. Data are the mean $\pm S D, n=6$. 
A

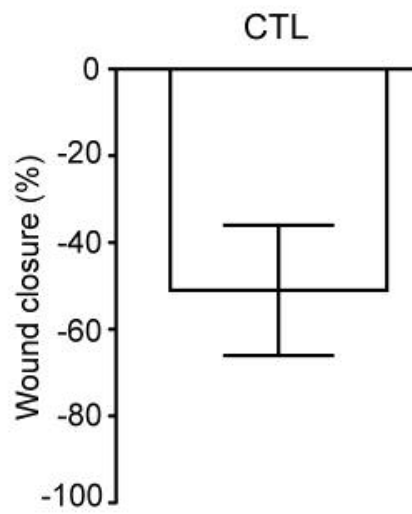

C
MCF-10A

Lidocaine

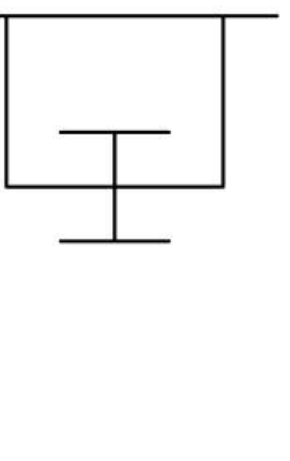

MDA-MB-231

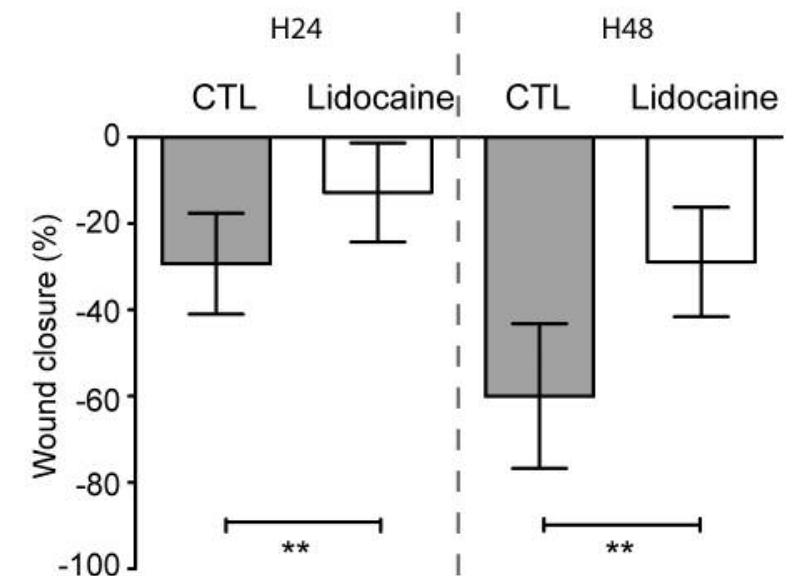

B

SKBr3

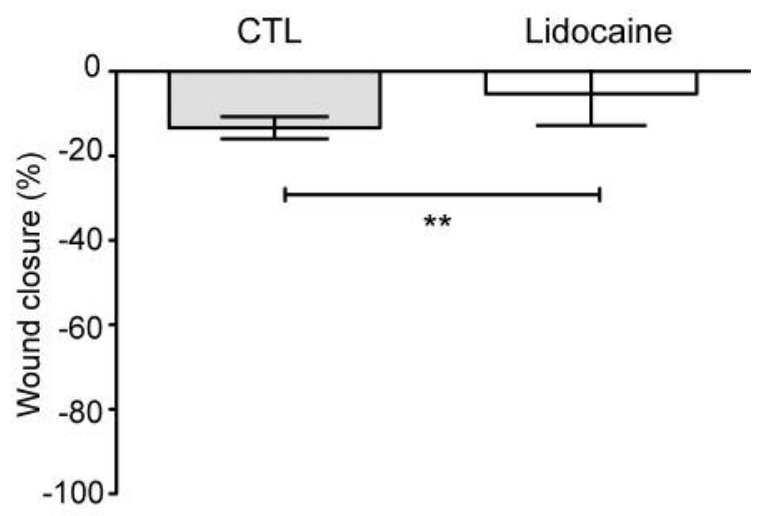

D

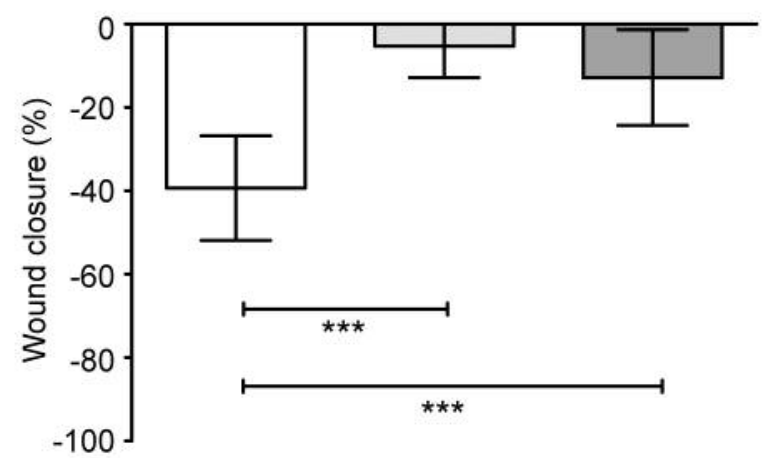

Figure 2. Effects of lidocaine on the cell migration of two tumor breast epithelial cell lines compared to a normal epithelial cell line. In vitro woundhealing assay was performed by a scratching cell monolayer then treating cells with lidocaine (Lido) or not (CTL). Quantitative analysis of the inhibitory effect on wound closure was assessed by comparing gap closure by lidocaine at $100 \mu \mathrm{M}$, on MCF-10A (A), SKBr3 (B) and MDA-MB$231(C)$ cell lines and comparison of all the cell lines after 24 and $48 h(D)$. Data were analyzed by unpaired t-test (A-C): Significantly different at $* * p<0.01$ for SKBr3 and ***p<0.001 for MDA-MB-231, or one-way repeated measures ANOVA $(D): p<0.001$. ***Significantly different at Dunnett test $p<0.001$. Data are the mean $\pm S D, n=9$.

Lidocaine inhibits cell migration of different human breast cancer cell lines. A characteristic of breast cancer cells is their ability to migrate. We next studied cell migration in this series of cell lines using the wound-closure assay under control and lidocaine-treated conditions. Again, a single treatment of lidocaine was used. MCF-7 cells did not show any significant migratory ability (data not shown). In the human breast cancer cell lines SKBr3 and MDA-MB-231, migration was significantly inhibited in the lidocaine-treated group compared to the control group after $24 \mathrm{~h}$ of exposure (Figure 2B and C). A significant reduction of wound closure persisted after $48 \mathrm{~h}$ for MDA-MB-231 cells. No significant effect of lidocaine was observed in the normal breast epithelial cell line MCF-10A after $24 \mathrm{~h}$ of lidocaine treatment (Figure 2A). Of note, exposure to lidocaine at 0.1 $\mathrm{mM}$ resulted in a marked inhibition of the migration of both Sk-Br3 and MDA-MB-231 breast cancer cells when compared with MCF-10A cells (Figure 2D). Collectively, these results show that lidocaine had a predominant inhibitory effect on breast cancer cell migration.

Lidocaine reduces anchorage-independent growth of MDAMB-231 cells. We observed that MDA-MB231 cells were more sensitive to lidocaine action. To confirm this notion, 


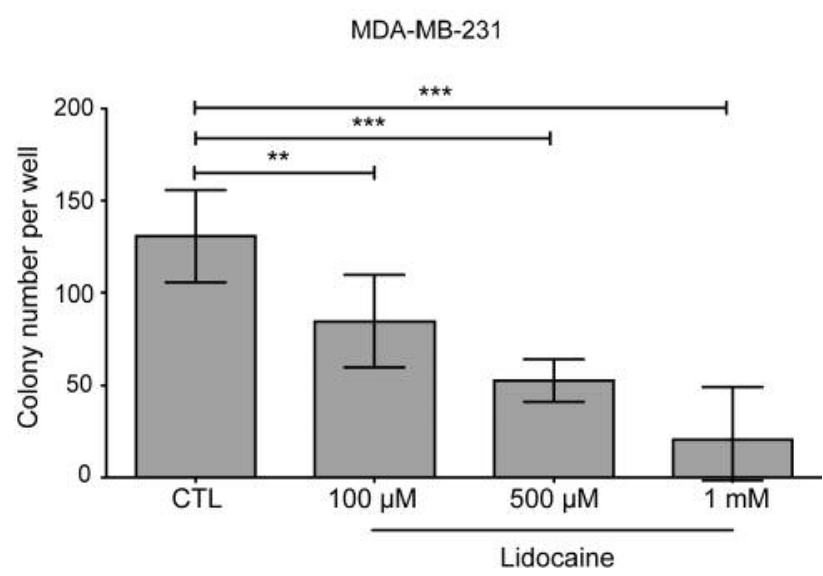

Figure 3. Effects of lidocaine on the anchorage-independent growth of the triple-negative cell line MDA-MB-231. Soft-agar assay was performed to assess the impact of lidocaine on MDA-MB-231 anchorage-independent growth using increasing concentration of lidocaine or vehicle alone. Data were analyzed by one-way repeated measures ANOVA: $p<0.001$ followed by a Dunnett-test: Significantly different at ${ }^{* *} p<0.001$ and ${ }^{* * *} p<0.001$. Data are the mean $\pm S D, n=9$.

we tested the impact of lidocaine on soft-agar anchorageindependent growth of MDA-MB-231 cells. Colony formation was tested using increasing concentration of lidocaine (Figure 3) at plating. No other lidocaine treatment was added during the experiment. We observed decreased colony numbers when cells were treated with lidocaine hydrochloride monohydrate. This is consistent with the effect of lidocaine on cell viability observed previously (Figure 1). Of note, a significant decrease in soft-agar cloning was observed using $100 \mu \mathrm{M}$ lidocaine at plating, a concentration lower than that needed to compromise viability (Figure 3 ). These data show that lidocaine compromised anchorageindependent growth of MDA-MB-231 cells.

Determination of median survival of mice injected intraperitoneally with MDA-MB-231 cells. We first assessed the duration of median survival in the carcinomatosis model using MDA-MB-231 cells. The end of the experiment was established by comparing lidocaine-treated animals with those treated with PBS alone according to the Sugarbaker experiment. As illustrated in Figure 4A, the median survival time was 34 days. Because two animals out of 10 reached experimental endpoints at day 29 , this time of treatment was selected for animal sacrifice to determine the PCI and tumor volumes under treatment.

Sequential intraperitoneal injection of lidocaine improves survival of mice with MDA-MB-231 peritoneal carcinomatosis. In a therapeutic attempt, lidocaine delivery began 2 weeks after carcinomatosis induction and was repeated every week to carry out a treatment over 3 weeks according to clinical repeated infusion of lidocaine in fibromyalgia (Figure 4B). With such a therapeutic regimen, lidocaine induced a significant improvement in animal survival when compared to controls (log-rank test with $p<0.05$ ) even if median survival was not significantly improved (30.5 versus 33.5 days, $p=0.07$ ). Survival of the treated animal was followed over 132 days (versus 50 days for the control group). No adverse effect was observed over the course of the experiment.

Lidocaine reduces tumor growth in vivo. To quantify the antitumor effects of lidocaine, tumor volumes and the extent of peritoneal carcinomatosis were measured in a separate experiment. Carcinomatosis parameters were investigated 29 days after tumor cell inoculation as determined in the first in vivo experiment. After sacrifice, the whole abdominal cavity was examined and scored in 13 predetermined areas for the presence and the grade of peritoneal carcinomatosis importance. All the nodules were then removed and their global volume was measured. Intraperitoneal injection of lidocaine significantly reduced the PCI: $7.20 \pm 2.07$ versus $17.40 \pm 3.98$ in controls $(p=0.02)$ (Figure 4C). But the reduction of the intraperitoneal volume observed with lidocaine $\left(0.395 \pm 0.290 \mathrm{~cm}^{3}\right)$ even if it seemed obvious was not significant when it was compared to the mean volume for the control group $\left(0.776 \pm 0.310 \mathrm{~cm}^{3}, p=0.17\right)$ (Figure $4 \mathrm{D})$, due to the significant standard deviation of the global tumor burden observed in the two investigated groups.

Collectively, these data show that repeated intraperitoneal injections of lidocaine delayed development of peritoneal carcinomatosis resulting in a prolonged survival for the treated group.

\section{Discussion}

The main findings of the in vitro study are that lidocaine had inhibitory effects on breast cancer cell viability and migration. Lidocaine also reduced anchorage-independent growth of MDA-MB-231 cells. A preclinical study in mice showed that sequential intraperitoneal injections of lidocaine reduced tumor growth and improved survival of mice with MDA-MB-231 peritoneal carcinomatosis.

Lidocaine action was measured in vitro, using a panel of human breast cell lines including lines that are representative of the principal breast cancer subtypes (28). In addition, we used the MCF10-A cell line, derived from human fibrocystic mammary tissue, that exhibits immortality and is considered a normal epithelial cell line (37). The MCF-7 human cell line was obtained from pleural effusion derived from a breast carcinoma, and is positive for expression of ER and PgR and represents the luminal subtype of breast cancer $(38,39)$. The SKBR3 cell line was derived from a pleural effusion from 

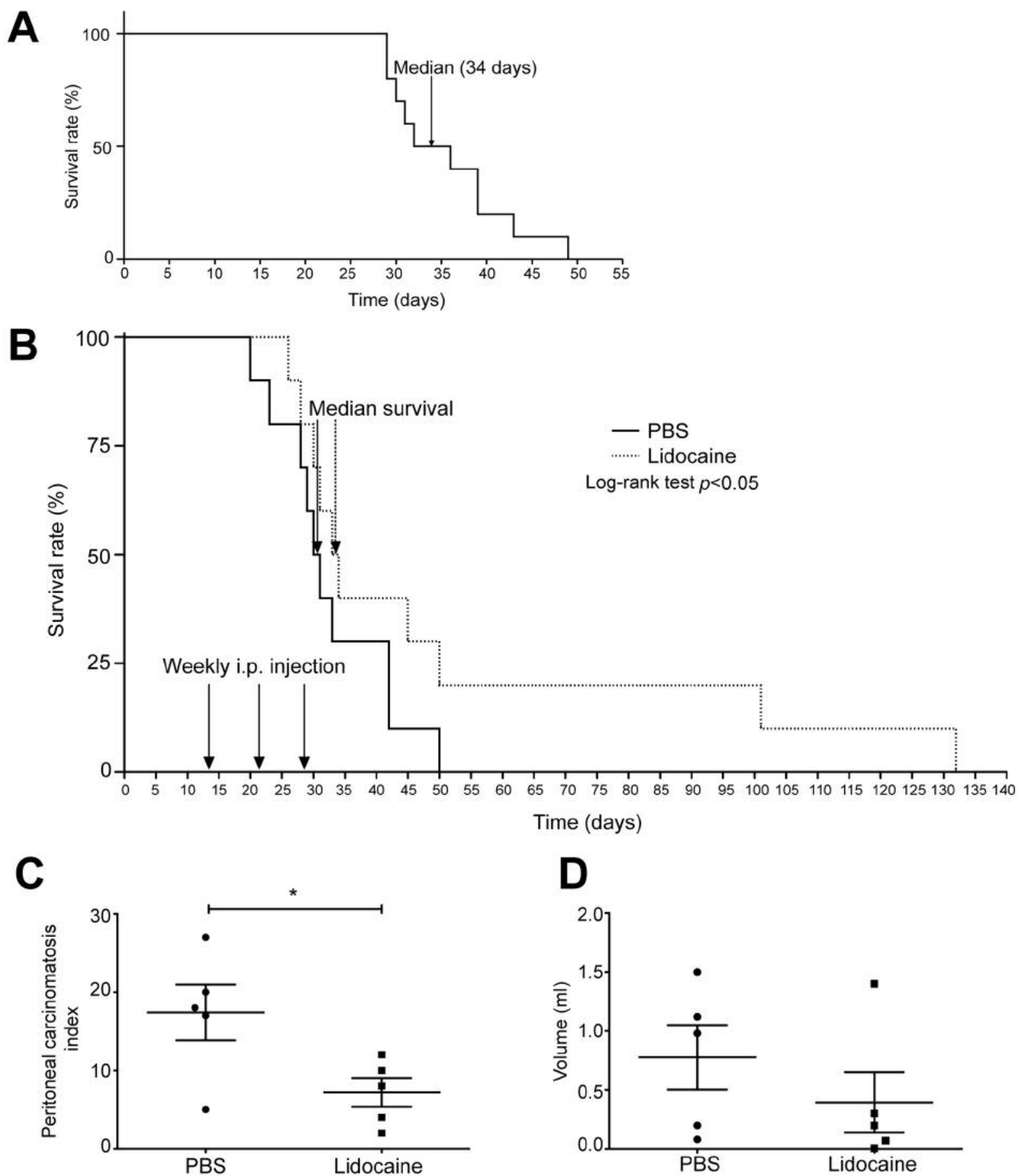

Figure 4. In vivo effects of intraperitoneal injections of lidocaine. A: Determination of median survival of mice injected intraperitoneally with MDA-MB-231 cells $(n=10)$. Animal survival was monitored over a period of 49 days and is presented as Kaplan-Meier curve. Median survival was 34 days. B: Survival of animals bearing peritoneal carcinomatosis generated by injection of MDA-MB 231 tumor cells treated with lidocaine or phosphate-buffered saline (PBS). Mice bearing peritoneal carcinomatosis were divided into two groups ( $n=10)$ and treated with PBS (control) or lidocaine administered weekly from 2 to 5 weeks after carcinomatosis induction. Animal survival was monitored over a period of 132 days and is presented as Kaplan-Meier curves, with median survival and p-values. C and D: Quantitative in-vivo tumor effect of lidocaine application. Mice bearing peritoneal carcinomatosis were divided into two groups $(n=5)$ and treated with PBS (control) or lidocaine administered weekly from 2 to 5 weeks after carcinomatosis induction and then were euthanatized for carcinomatosis grading. C: Effect of lidocaine on Peritoneal Carcinomatosis Index (PCI, SEM) according to Sugarbaker scaling adapted to small animals, unpaired t-test: *Significantly different at p<0.05. D: Effect of lidocaine on intraperitoneal tumor volumes (in $\mathrm{ml}$, SEM), unpaired t-test showed no significant differences. 
an adenocarcinoma originating in the breast and overexpresses the ERBB2 (HER2) gene product and represents the HER2 subtype (40). The MDA-MB-231 cell line is a triple-negative breast cancer (TNBC) cell line frequently used for investigation of the TNBC subtypes. TNBC represents approximately $15 \%$ of all breast cancer; this subtype has a poor outcome compared to the other subtypes and represents a therapeutic challenge $(41,42)$.

Our study showed that lidocaine can compromise the viability of all the tested cell lines in vitro but different sensitivity was observed among them. While a high concentration of lidocaine (above $1 \mathrm{mM}$ ) limited cell viability for all the cell lines tested, the TBNC line was more sensitive as its viability was compromised at a lower concentration $(0.5 \mathrm{mM})$. These results suggest that the mechanisms of action of lidocaine on cell viability are different among distinct cell lines. These results are consistent with findings of breast $(16,19,22)$ and other cancer cell types including A549 and H520 human non-small cell lung cancer cells (20), 8505C and K1 human thyroid cancer cells (17), PC-3 prostatic cancer cells and ES-2 ovarian cancer cells (19).

We noted that lidocaine inhibited migration of the HER2 and TNBC tumor breast epithelial cells without compromising migration of the normal breast epithelial cells. Of interest, the anti-migratory effects of lidocaine were observed at a low concentration $(100 \mu \mathrm{M})$. This concentration had no effect on cell viability. These results on viability were obtained at lower concentrations and after shorter exposure than those tested in previous experiments using different human cell lines $(17,20)$ or breast cancer cell lines (16), thus confirming the notion that lidocaine has a direct antitumor potential. In addition, the conditions used in our experiments are relevant to clinical application during surgery. Moreover, another study using MDA-MB-231 cells did not observe any cytotoxicity of lidocaine for a longer exposure of $24 \mathrm{~h}$ at $1 \mathrm{mM}$ (19). In addition, using the TNBC cell line, we showed that lidocaine reduced tumorigenicity in vitro, as assayed by anchorage independent cell growth. Again, the antitumorigenic effect of lidocaine was observed at a concentration not affecting the viability of this cell line.

Of interest, we observed that the TNBC cell line MDA-MB231 was more sensitive to the direct inhibitory action of lidocaine. Given the high metastatic potential of this cell line and its sensitivity to lidocaine, we chose this TNBC cell line to investigate the effects of lidocaine in vivo. But considering that the concentration of $100 \mu \mathrm{M}$ is higher than those considered to cause lidocaine toxicity in plasma [namely 5 $\mu \mathrm{g} / \mathrm{ml}(15)$ or approximately $21 \mu \mathrm{M}$ ] an in vitro to in vivo translation experiment was strongly required to connect in vitro observations with clinical application. We chose an intraperitoneal xenograft in nude mice as a preclinical model (43). SCID mice express normal population and function of natural killer, macrophage and granulocyte cells (44) and lidocaine also has indirect antitumor properties by enhancing natural killer cell functions (23) and modulating the tumor microenvironment (25-27). We therefore assumed that lidocaine may have additive protective effects against tumor growth at relevant systemic concentrations. To measure the impact of lidocaine treatment on tumor growth, we treated mice during the course of disease progression in order to evaluate the properties of lidocaine as an adjuvant therapy. To determine the dose $(31,32)$ and the mode of administration of lidocaine (33) in this preclinical cancer model, we adapted protocols used in clinical practice. The dose of $100 \mathrm{mg} / \mathrm{kg}$ of lidocaine in mice corresponds to a dose of $8 \mathrm{mg} / \mathrm{kg}$ in humans according to the dose translation based on body surface area (32). In addition, in a pharmacokinetic study, the intraperitoneal administration of $400 \mathrm{mg}$ lidocaine (i.e. $8 \mathrm{mg} / \mathrm{kg}$ in a $50 \mathrm{~kg}$ patient) was safe (45). We show that intraperitoneal lidocaine injection reduced breast cancer cell tumor burden and improves survival in the peritoneal carcinomatosis model. Moreover, no adverse effect was observed in treated mice, confirming the potential of lidocaine in clinical use.

Intraperitoneal administration of lidocaine presents many advantages: firstly, it has shown comparable efficacy as intravenous infusion in elective abdominal hysterectomy (46) or laparoscopic appendectomy (47) in term of analgesia; secondly, it could be a more efficient route for systemic chemotherapy (48), and thirdly, as our xenograft model is on of peritoneal carcinomatosis, tumors were directly exposed to lidocaine as minimal residual disease could be achieved with minimal invasive anesthetic techniques (i.e. surgical wound infiltration or infusion) (49). Along this line, the effects of peritumoral infiltration of lidocaine prior to excision are currently being assessed in a clinical trial (NCT01916317) with the aim of reducing the dissemination of cancer cells during surgery and improving the disease-free interval. Taken together, our study suggests that lidocaine may also be administered intraperitoneally to prevent peritoneal carcinomatosis even if rarely breast cancer metastasizes within the peritoneal cavity (50).

The antitumor effects of lidocaine at the molecular level remain unclear. Of interest, our study indicates that lidocaine had a greater antitumor effect on the MDA-MB-231 cell line, this line is known to overexpress the voltage-gated sodium channel (VGSC) (51), a canonical pharmacological target of lidocaine (52). The VGSC is composed of different subunits including the Nav1.5 $\alpha$ subunit which can be inactivated by lidocaine in cardiomyocytes (53). Consistent with the notion that lidocaine might exert its antitumor effects through this subunit, other reports showed that inactivating Nav1.5 $\alpha$ subunit with a different drug (e.g. phenytoin) can have antitumor effects in vitro (54) and in vivo (55). Perhaps this hypothesis should be further investigated, as phenytoin and lidocaine seem to have different binding sites on VGSC (52, 56). In addition, overexpression of the Nav1.5 subunit was 
reported in human breast cancer biopsy sections (57). Other hypotheses concerning other ion channels should also be explored. Indeed, the transient receptor potential channel, subfamily V, member 6 (TRPV-6), a calcium channel, may play a key role as lidocaine can inhibit the migration and invasion of TRPV6-expressing cells and reduce the intracellular-free $\mathrm{Ca}^{2+}$ level (19). Altogether, we can speculate that targeting VGSC using a well-characterized anesthetic drug such as lidocaine may be a good strategy to reduce metastatic risk (58).

Lidocaine is known to have analgesic, anti-hyperalgesic, and anti-inflammatory effects $(14,59)$. Indeed, intravenous lidocaine infusion administered as a component of multimodal analgesia is reported to reduce opioid requirements and improve pain relief (14). In a small clinical trial of patients undergoing breast cancer surgery, lidocaine infusion failed to demonstrate any significant effect on postoperative pain (60) but another trial showed that perioperative lidocaine infusion reduced the incidence of persistent postoperative pain (24). However, a recent metaanalysis concluded that the analgesic benefits occurred only in patients undergoing abdominal surgery (laparoscopic and open approach), and not for other surgical procedures (15). Despite the fact that the antitumor mechanisms of lidocaine are still unclear, using lidocaine during surgery might be beneficial to limit surgery-driven cancer cell escape from dormancy $(5,6)$ or tumor cell shedding $(3,4)$, and clinical trials are needed to include lidocaine in a repurposing drug program (61) notably to manage TNBC which does not respond to hormonal therapy (such as tamoxifen or aromatase inhibitors) or therapies that target HER2 receptors (such as trastuzumab).

In conclusion, the findings of these in vitro and in vivo experiments suggest that lidocaine may have a protective effect against breast cancer cells. However, the molecular mechanisms of lidocaine in cancer are unclear. The findings presented here, of potential beneficial impact of lidocaine on cancer should be strengthened by additional preclinical and clinical studies.

\section{Funding}

This study was funded by the grant ANR-10-LABX-0030-INRT, a French State fund managed by the Agence Nationale de la Recherche under the frame program "Investissements d'Avenir" labelled ANR10-IDEX-0002-02. Thiên-Nga Chamaraux-Tran is an IGBMC International Ph.D. Program fellow supported by LabEx INRT funds. The Authors declare receiving funds from the charity Seins et Vie and the Société Française d'Anesthésie-Réanimation (SFAR).

\section{Conflict of Interest}

G.P. Joshi is a consultant for Pacira, Baxter, Mallincrodt and Merck Pharmaceuticals. The others Authors declare that they have no conflict of interest in regard to this study.

\section{Ethical Approval}

All applicable international, national, and institutional guidelines for the care and use of animals were followed. All animal experiments were carried out according to the revised European Community directive $(2010 / 63 / \mathrm{EU}$, September 24, 2010) on the protection of animals used for scientific purposes and with an ethical agreement (no. 38.2012.01.046) according to the French transposition of the European Community directive. This article does not include any studies with human participants performed by any of the Authors.

\section{Acknowledgements}

The Authors would like to thank Betty Heller and Corinne Wendling (IGBMC institute) for their help with the cell culture, Léa Wilhelm for the figure layouts and Marie-Christine Rio for her scientific support and discussion.

\section{Presentation}

Preliminary data for this study were presented as a poster presentation at the 2014 and 2015 American Society of Anesthesiologists Annual Meeting, and as oral communication at the 2014 and 2015 French Society of Anesthesia and Intensive Care Annual Congress.

\section{References}

1 Ferlay J, Soerjomataram I, Dikshit R, Eser S, Mathers C, Rebelo M, Parkin DM, Forman D and Bray F: Cancer incidence and mortality worldwide: sources, methods and major patterns in GLOBOCAN 2012. Int J Cancer 136: E359-386, 2015.

2 Kummerow KL, Du L, Penson DF, Shyr Y and Hooks MA: Nationwide trends in mastectomy for early-stage breast cancer. JAMA Surg 150: 9-16, 2015.

3 Choy A and McCulloch P: Induction of tumour cell shedding into effluent venous blood breast cancer surgery. Br J Cancer 73: 79-82, 1996.

4 Camara O, Kavallaris A, Noschel H, Rengsberger M, Jorke C and Pachmann K: Seeding of epithelial cells into circulation during surgery for breast cancer: the fate of malignant and benign mobilized cells. World J Surg Oncol 4: 67, 2006.

5 Retsky MW, Demicheli R, Hrushesky WJM, Baum M and Gukas ID: Dormancy and surgery-driven escape from dormancy help explain some clinical features of breast cancer. APMIS 116: 730-741, 2008.

6 Benish M and Ben-Eliyahu S: Surgery as a Double-Edged Sword: A clinically feasible approach to overcome the metastasis-promoting effects of surgery by blunting stress and prostaglandin responses. Cancers 2: 1929-1951, 2010.

7 Sekandarzad MW, van Zundert AAJ, Lirk PB, Doornebal CW and Hollmann MW: Perioperative anesthesia care and tumor progression. Anesth Analg 124: 1697-1708, 2017.

8 Exadaktylos AK, Buggy DJ, Moriarty DC, Mascha E and Sessler DI: Can anesthetic technique for primary breast cancer surgery affect recurrence or metastasis? Anesthesiology 105: 660-664, 2006.

9 Weng M, Chen W, Hou W, Li L, Ding M and Miao C: The effect of neuraxial anesthesia on cancer recurrence and survival after cancer surgery: an updated meta-analysis. Oncotarget 7: 1526215273, 2016. 
10 Singleton PA, Moss J, Karp DD, Atkins JT and Janku F: The mu opioid receptor: A new target for cancer therapy?: The mu opioid receptor in cancer. Cancer 121: 2681-2688, 2015.

11 Cronin-Fenton DP, Heide-Jørgensen U, Ahern TP, Lash TL, Christiansen PM, Ejlertsen B, Sjøgren P, Kehlet H and Sørensen HT: Opioids and breast cancer recurrence: A Danish populationbased cohort study. Cancer 121: 3507-3514, 2015.

12 Piegeler T, Votta-Velis EG, Liu G, Place AT, Schwartz DE, Beck-Schimmer B, Minshall RD and Borgeat A: Antimetastatic potential of amide-linked local anesthetics. Anesthesiology 117: 548-559, 2012.

13 Votta-Velis EG, Piegeler T, Minshall RD, Aguirre J, BeckSchimmer B, Schwartz DE and Borgeat A: Regional anaesthesia and cancer metastases: the implication of local anaesthetics. Acta Anaesthesiol Scand 57: 1211-1229, 2013.

14 Joshi GP, Schug SA and Kehlet H: Procedure-specific pain management and outcome strategies. Best Pract Res Clin Anaesthesiol 28: 191-201, 2014.

15 Weibel S, Jokinen J, Pace NL, Schnabel A, Hollmann MW, Hahnenkamp K, Eberhart LHJ, Poepping DM, Afshari A and Kranke P: Efficacy and safety of intravenous lidocaine for postoperative analgesia and recovery after surgery: a systematic review with trial sequential analysis. Br J Anaesth 116: 770-783, 2016.

16 Chang Y-C, Liu C-L, Chen M-J, Hsu Y-W, Chen S-N, Lin C-H, Chen C-M, Yang F-M and Hu M-C: Local anesthetics induce apoptosis in human breast tumor cells. Anesth Analg 118: 116124, 2014

17 Chang Y-C, Hsu Y-C, Liu C-L, Huang S-Y, Hu M-C and Cheng S-P: Local Anesthetics induce apoptosis in human thyroid cancer cells through the mitogen-activated protein kinase pathway. PloS One 9: e89563, 2014.

18 Piegeler T, Schläpfer M, Dull RO, Schwartz DE, Borgeat A, Minshall RD and Beck-Schimmer B: Clinically relevant concentrations of lidocaine and ropivacaine inhibit $\mathrm{TNF} \alpha-$ induced invasion of lung adenocarcinoma cells in vitro by blocking the activation of AKT and focal adhesion kinase. Br J Anaesth 115: 784-791, 2015.

19 Jiang Y, Gou H, Zhu J, Tian S and Yu L: Lidocaine inhibits the invasion and migration of TRPV6-expressing cancer cells by TRPV6 down-regulation. Oncol Lett 12: 1164-1170, 2016.

20 Wang H-W, Wang L-Y, Jiang L, Tian S-M, Zhong T-D and Fang $\mathrm{X}-\mathrm{M}$ : Amide-linked local anesthetics induce apoptosis in human non-small cell lung cancer. J Thorac Dis 8: 2748-2757, 2016.

21 Xing W, Chen D-T, Pan J-H, Chen Y-H, Yan Y, Li Q, Xue R-F, Yuan Y-F and Zeng W-A: Lidocaine induces apoptosis and suppresses tumor growth in human hepatocellular carcinoma cells in vitro and in a xenograft model in vivo. Anesthesiol J Am Soc Anesthesiol 126: 868-881, 2017.

$22 \mathrm{Li} \mathrm{K}$, Yang J and Han X: Lidocaine sensitizes the cytotoxicity of cisplatin in breast cancer cells via up-regulation of $R A R \beta 2$ and RASSF1A demethylation. Int J Mol Sci 15: 23519-23536, 2014.

23 Ramirez MF, Tran P and Cata JP: The effect of clinically therapeutic plasma concentrations of lidocaine on natural killer cell cytotoxicity. Reg Anesth Pain Med 40: 43-48, 2015.

24 Grigoras A, Lee P, Sattar F and Shorten G: Perioperative intravenous lidocaine decreases the incidence of persistent pain after breast surgery. Clin J Pain 28: 567-572, 2012.

25 Lucchinetti E, Awad AE, Rahman M, Feng J, Lou P-H, Zhang L, Ionescu L, Lemieux H, Thébaud B and Zaugg M: Antiproliferative effects of local anesthetics on mesenchymal stem cells: potential implications for tumor spreading and wound healing. Anesthesiology 116: 841-856, 2012.

26 Gray A, Marrero-Berrios I, Ghodbane M, Maguire T, Weinberg J, Manchikalapati D, SchianodiCola J, Schloss RS and Yarmush J: Effect of local anesthetics on human mesenchymal stromal cell secretion. Nano LIFE 5: 1550001-1550014, 2015.

27 Gray A, Marrero-Berrios I, Weinberg J, Manchikalapati D, SchianodiCola J, Schloss RS and Yarmush J: The effect of local anesthetic on pro-inflammatory macrophage modulation by mesenchymal stromal cells. Int Immunopharmacol 33: 48-54, 2016.

28 Lacroix M and Leclercq G: Relevance of breast cancer cell lines as models for breast tumours: an update. Breast Cancer Res Treat 83: 249-289, 2004.

29 Mosmann T: Rapid colorimetric assay for cellular growth and survival: Application to proliferation and cytotoxicity assays. J Immunol Methods 65: 55-63, 1983.

30 Marks DC, Belov L, Davey MW, Davey RA and Kidman AD: The MTT cell viability assay for cytotoxicity testing in multidrug-resistant human leukemic cells. Leuk Res 16: 11651173, 1992.

31 Narchi P, Benhamou D and Fernandez H: Intraperitoneal local anaesthetic for shoulder pain after day-case laparoscopy. Lancet 338: 1569-1570, 1991.

32 Reagan-Shaw S, Nihal M and Ahmad N: Dose translation from animal to human studies revisited. FASEB J 22: 659-661, 2008.

33 Marks DM and Newhouse A: Durability of benefit from repeated intravenous lidocaine infusions in fibromyalgia patients: A case series and literature review. Prim Care Companion CNS Disord. 17: 4088, 2015.

34 Machin D, Campbell M, Fayers P and Pinol A: Sample Size Tables for Clinical Studies (Scand Edition). Oxford, Blackwell Science, 1997.

35 Otto J, Jansen PL, Lucas S, Schumpelick V and Jansen M: Reduction of peritoneal carcinomatosis by intraperitoneal administration of phospholipids in rats. BMC Cancer 7: 104, 2007.

36 Kaplan EL and Meier P: Nonparametric estimation from incomplete observations. J Am Stat Assoc 53: 457-481, 1958.

37 Soule HD, Maloney TM, Wolman SR, Peterson WD, Brenz R, McGrath CM, Russo J, Pauley RJ, Jones RF and Brooks SC: Isolation and characterization of a spontaneously immortalized human breast epithelial cell line, MCF-10. Cancer Res 50: 60756086, 1990.

38 Soule HD, Vazguez J, Long A, Albert S and Brennan M: A human cell line from a pleural effusion derived from a breast carcinoma. J Natl Cancer Inst 51: 1409-1416, 1973.

39 Hegde SM, Kumar MN, Kavya K, Kumar KMK, Nagesh R, Patil RH, Babu RL, Ramesh GT and Sharma SC: Interplay of nuclear receptors (ER, PR, and GR) and their steroid hormones in MCF-7 cells. Mol Cell Biochem 422: 109-120, 2016.

40 Trempe GL: Human breast cancer in culture. Recent Results Cancer Res 57: 33-41, 1976.

41 Cailleau R, Young R, Olivé M and Reeves WJ Jr.: Breast tumor cell lines from pleural effusions. J Natl Cancer Inst 53: 661-674, 1974.

42 Chavez KJ, Garimella SV and Lipkowitz S: Triple-negative breast cancer cell lines: one tool in the search for better treatment of triple-negative breast cancer. Breast Dis 32: 35-48, 2010 . 
43 Yao Y, Zhou Y, Su X, Dai L, Yu L, Deng H, Gou L and Yang J: Establishment and characterization of intraperitoneal xenograft models by co-injection of human tumor cells and extracellular matrix gel. Oncol Lett 10: 3450-3456, 2015.

44 Custer RP, Bosma GC and Bosma MJ: Severe combined immunodeficiency (SCID) in the mouse. Pathology, reconstitution, neoplasms. Am J Pathol 120: 464-477, 1985.

45 Narchi P, Benhamou D, Bouaziz H, Fernandez H and Mazoit JX: Serum concentrations of local anaesthetics following intraperitoneal administration during laparoscopy. Eur J Clin Pharmacol 42: 223-225, 1992.

46 Samimi S, Taheri A and Davari Tanha F: Comparison between intraperitoneal and intravenous lidocaine for postoperative analgesia after elective abdominal hysterectomy, a double-blind placebo controlled study. J Fam Reprod Health 9: 193-198, 2015.

47 Kim TH, Kang H, Hong JH, Park JS, Baek CW, Kim JY, Jung $\mathrm{YH}$ and Kim HK: Intraperitoneal and intravenous lidocaine for effective pain relief after laparoscopic appendectomy: a prospective, randomized, double-blind, placebo-controlled study. Surg Endosc 25: 3183-3190, 2011.

48 Miyagi Y, Fujiwara K, Kigawa J, Itamochi H, Nagao S, Aotani E, Terakawa N, Kohno I and Sankai Gynecology Study Group (SGSG): Intraperitoneal carboplatin infusion may be a pharmacologically more reasonable route than intravenous administration as a systemic chemotherapy. A comparative pharmacokinetic analysis of platinum using a new mathematical model after intraperitoneal vs. intravenous infusion of carboplatin - a Sankai Gynecology Study Group (SGSG) study. Gynecol Oncol 99: 591-596, 2005.

49 Cheng GS and Ilfeld BM: A review of postoperative analgesia for breast cancer surgery. Pain Manag 6: 603-618, 2016.

50 Moore E, Roylance R and Rosenthal A: Breast cancer metastasising to the pelvis and abdomen: what the gynaecologist needs to know. Int J Obstet Gynaecol 119: 788-794, 2012.

51 Fraser SP, Ozerlat-Gunduz I, Onkal R, Diss JKJ, Latchman DS and Djamgoz MBA: Estrogen and non-genomic upregulation of voltage-gated $\mathrm{Na}(+)$ channel activity in MDA-MB-231 human breast cancer cells: role in adhesion. J Cell Physiol 224: 527$539,2010$.

52 Fozzard HA, Sheets MF and Hanck D: The sodium channel as a target for local anesthetic drugs. Front Pharmacol 2: 68, 2011.
53 Wang Y, Mi J, Lu K, Lu Y and Wang K: Comparison of gating properties and use-dependent block of Nav1.5 and Nav1.7 channels by anti-arrhythmics mexiletine and lidocaine. PLoS One 10: e0128653, 2015.

54 Yang M, Kozminski DJ, Wold LA, Modak R, Calhoun JD, Isom LL and Brackenbury WJ: Therapeutic potential for phenytoin: targeting Nav1.5 sodium channels to reduce migration and invasion in metastatic breast cancer. Breast Cancer Res Treat 134: 603-615, 2012.

55 Nelson M, Yang M, Dowle AA, Thomas JR and Brackenbury WJ: The sodium channel-blocking antiepileptic drug phenytoin inhibits breast tumour growth and metastasis. Mol Cancer 14: 13, 2015.

56 Boiteux C, Vorobyov I, French RJ, French C, Yarov-Yarovoy V and Allen TW: Local anesthetic and antiepileptic drug access and binding to a bacterial voltage-gated sodium channel. Proc Natl Acad Sci USA 111: 13057-13062, 2014.

57 Roger S, Gillet L, Le Guennec J-Y and Besson P: Voltage-gated sodium channels and cancer: Is excitability their primary role? Front Pharmacol 6: 152, 2015.

58 Koltai T: Voltage-gated sodium channel as a target for metastatic risk reduction with re-purposed drugs. F1000Res 4: 297, 2015.

59 van der Wal SEI, van den Heuvel SAS, Radema SA, van Berkum BFM, Vaneker M, Steegers MAH, Scheffer GJ and Vissers KCP: The in vitro mechanisms and in vivo efficacy of intravenous lidocaine on the neuroinflammatory response in acute and chronic pain. Eur J Pain 20: 655-674, 2016.

60 Terkawi AS, Durieux ME, Gottschalk A, Brenin D and Tiouririne M: Effect of intravenous lidocaine on postoperative recovery of patients undergoing mastectomy: a double-blind, placebo-controlled randomized trial. Reg Anesth Pain Med 39: 472-477, 2014.

61 Pantziarka P, Bouche G, Meheus L, Sukhatme V, Sukhatme VP and Vikas P: The repurposing drugs in oncology (ReDO) project. Ecancermedicalscience 8: 442, 2014.
Received October 4, 2017

Revised October 29, 2017 Accepted November 1, 2017 